\title{
Resiliency in Adolescents at High Risk for Substance Abuse: Flexible Adaptation via Subthalamic Nucleus and Linkage to Drinking and Drug Use in Early Adulthood
}

\author{
Barbara J. Weiland, Joel T. Nigg, Robert C. Welsh, Wai-Ying W. Yau, Jon-Kar Zubieta, \\ Robert A. Zucker, and Mary M. Heitzeg
}

\begin{abstract}
Introduction: The personality trait resiliency is the ability to flexibly adapt impulse control relative to contextual demand. Low resiliency has been linked to later alcohol/drug problems. The underlying psychological and neural mechanisms are unknown, but neurocomputational models suggested relations between resiliency and working memory. Cortical-striatal connectivity has been proposed to underlie adaptive switches between cautious and risky behaviors.

Methods: Working memory was probed in sixty-seven 18- to 22-year-olds from a larger community study of alcoholism, using the $n$-back task during functional magnetic resonance imaging. Functional connectivity between task-related regions was investigated with psychophysiological interaction analysis. Resiliency was measured in early teen years and related to early adulthood measures of drinking/ drug use, task activation, and connectivity. Relationships with risk factors, including family history, age of drinking onset, and number of alcohol problems, were also investigated.

Results: Higher resiliency was related to lower levels of substance use, fewer alcohol problems, and better working memory performance. Whole-brain regression revealed resiliency negatively correlated with activation of subthalamic nucleus (STN) and pallidum during the $n$-back. High and Low resiliency quartile groups ( $n=17$ each) differed in coupling strength between STN and median cingulate cortex, a region of reduced activation during working memory. The high resiliency group had later onset of drinking, fewer alcohol problems, had used fewer illicit drugs, and were less likely to smoke cigarettes than their low resiliency counterparts.

Conclusions: These findings suggest that resiliency in early adolescence may protect against alcohol problems and drug use, although the direction of this effect is currently unknown. This protective factor may relate to executive functioning as supported by the finding of a neural link shared between resiliency and working memory in basal ganglia structures. The STN, a key basal ganglia structure, may adaptively link flexible impulse control with cognitive processing, potentially modulating substance use outcomes.
\end{abstract}

Key Words: Resiliency, Substance Use, Working Memory, Subthalamic Nucleus, Functional Magnetic Resonance Imaging, Psychophysiological Interaction.

$\mathrm{R}$ ESILIENCY IS DEFINED as the ability for flexible adaptation of psychological control functions appropriate to local context (Block et al., 1988; Eisenberg and Morris, 2002). For example, someone with high resiliency could be both impulsive at a party and appropriately

From the Department of Psychiatry ( $B J W, R C W, W-Y W Y, J-K Z$, RAZ, MMH), The University of Michigan, Ann Arbor, Michigan; Addiction Research Center (BJW, RAZ, MMH), The University of Michigan, Ann Arbor, Michigan; Department of Psychiatry (JTN), Oregon Health \& Science University, Portland, Oregon; Department of Radiology ( $R C W, J-K Z)$, The University of Michigan, Ann Arbor, Michigan; and Molecular \& Behavioral Neuroscience Institute ( $W-Y W Y$, $J-K Z)$, The University of Michigan, Ann Arbor, Michigan.

Received for publication May 10, 2011; accepted November 29, 2011.

Reprint requests: Barbara Weiland, PhD, UM Addiction Research Center, Department of Psychiatry, The University of Michigan, Rachel Upjohn Building, 4250 Plymouth Road, Ann Arbor, MI 48109; Tel.: 734232-0287; Fax: 734-998-7992; E-mail: bweiland@umich.edu

Copyright $($ C 2012 by the Research Society on Alcoholism.

DOI: 10.1111/j.1530-0277.2012.01741.x controlled in a classroom and able to cope with stress by modulating impulse control. Conversely, someone with low resiliency might be over- or undercontrolled in all settings, adapting less effectively to stress and unable to modulate behavior.

We previously examined developmental trajectories of resiliency relative to substance use (Wong et al., 2006) as part of the Michigan Longitudinal Study (MLS), an ongoing, prospective community study of families with parental alcoholism and contrast nonalcoholic families (Zucker et al., 1996, 2000). That study found low resiliency, measured at 3 to 4 years, was associated with early alcohol use (by age 14) and drunkenness by age of 17 years (Wong et al., 2006), similar to a general community study that found low resiliency in preschoolers related to drug use in early adolescence (Block et al., 1988). Resiliency, which remained stable from preschool through adolescence (Wong et al., 2006), may represent an important component among the psychological strategies needed to cope with the range of personal, social, and cognitive challenges facing today's youth. 
As temperament and executive function have been identified as precursors and mediators of psychopathology (Barkley, 1997; Eisenberg et al., 2000; Nigg, 2000), another MLS study investigated and found consistent relations between resiliency and executive functioning (Martel et al., 2007). Resiliency may share underpinnings with executive abilities, perhaps enhancing its development, or interacting with it, to shape cognition and social adaptation. Indeed, resiliency and executive functioning contributed to adolescent outcomes in an additive, incremental fashion, as opposed to overlapping in their effects (Martel et al., 2007), supporting the hypothesis that they are to some degree separable.

However, executive function is itself a broad, underspecified construct, likely including response suppression, planning, mental set shifting, and working memory (e.g., Pennington and Ozonoff, 1996). This study examines neural responses during working memory which has been identified as relevant to impulsive behavior (Finn et al., 1999) and substance use outcomes (Corral et al., 1999; Ozkaragoz et al., 1997). Neuroimaging studies show that working memory processes involve activation of a network including the basal ganglia and anterior cingulate, parietal, and prefrontal cortices (Chang et al., 2007; Owen et al., 2005; Smith and Jonides, 1997) accompanied by deactivation in the "default network" including posterior cingulate and medial frontal cortices (Greicius and Menon, 2004; Raichle et al., 2001; Spadoni et al., 2008), similar to other executive tasks. It has been suggested that resiliency is related to an anterior attention system involving cingulate and prefrontal cortices and their projections to the basal ganglia and thalamus (Eisenberg et al., 2003; Rothbart et al., 2000).

Neurocomputational models propose the basal ganglia performs dynamic gating of working memory via disinhibition to allow the prefrontal cortex to focus on task demands (O'Reilly and Frank, 2006). Inhibitory control of the basal ganglia is influenced by the subthalamic nucleus (STN) whose activity produces slower more accurate choices (Frank et al., 2007). The STN is believed to be dynamically modulated through "proactive inhibition" of sensorimotor responses by the medial prefrontal cortex, precuneus/posterior cingulate, inferior parietal cortex, as well as the dorsal anterior cingulate based on the degree of decision conflict (Ballanger et al., 2009; Botvinick et al., 2001; Bush et al., 1998; Frank, 2006; Yeung et al., 2004). In addition, changes in cortical-striatal connectivity are proposed to underlie adaptive switches between cautious and risky behaviors (Forstmann et al., 2010). We hypothesized, then, that resiliency may influence substance use outcomes via flexible adaptation entailing some of the same neural networks as working memory.

To test this hypothesis, resiliency, measured by observer ratings during early teen years, was examined in relation to brain activation during working memory and with selfreported drinking and drug use in young adulthood. We expected resiliency to be negatively related to both substance use and inhibitory activity in the cortico-striatal working memory pathway. We also hypothesized that resiliency would be linked with the measures of vulnerability to substance abuse, including family history of alcoholism (National Institute on Alcohol Abuse and Alcoholism, 2000), early onset of drinking (Grant and Dawson, 1997; Hingson et al., 2006), and higher levels of alcohol-related problems (Bonomo et al., 2004; Dick et al., 2011; Viner and Taylor, 2007). Using psychophysiological interaction (PPI) analysis (Friston et al., 1997), we evaluated functional coupling of regions associated with resiliency, proposing differences by level of resiliency (High vs. Low quartiles).

\section{MATERIALS AND METHODS}

\section{Participants}

Participants were 67 right-handed youth (43 men/24 women), aged 18.0 to 22.3 years (mean, $20.2 \pm 1.2$ ), recruited from the MLS of families with parental alcoholism ( $\mathrm{FH}+; 2 / 3$ of sample) and contrast nonalcoholic families (FH-; 1/3 of sample). Parental alcoholism was based on DSM-IV criteria. A detailed description regarding MLS recruitment strategy/assessment procedures can be found elsewhere (Zucker et al., 1996, 2000). Exclusionary criteria were the following: (i) any neurological, acute, uncorrected, or chronic medical illness; (ii) any current or recent (within 6 months) treatment with centrally active medications; or (iii) a history of psychosis or schizophrenia in first-degree relatives. Presence of most Axis I psychiatric or developmental disorders was also exclusionary. However, externalizing disorders (i.e., conduct disorder, attention deficit/hyperactivity disorder [ADHD], or prior substance use disorder) were not exclusionary, as these are on the same developmental spectrum with alcoholism risk (Krueger, 1999). In addition, participants were given a multidrug 5-panel urine screen before scanning and those with a positive drug screen were not included in this study. Participants gave written informed consent after explanation of the experimental protocol, as approved by the local Institutional Review Board.

\section{Measures}

Resiliency Measure. Resiliency was assessed by observer ratings using the California Child Q-Sort common language version (Block and Block, 1980; Caspi et al., 1992) for participants when they were 12 to 15 years (mean, $13.5 \pm 0.9$ ) as part of the ongoing MLS (Martel et al., 2007). The Q-sort was completed by clinically trained assessors, blinded to family history status of subjects, following a 3to 4-hour interview/testing protocol with the child (Shedler and Block, 1990). The Q-sort consists of 100 cards that must be placed in a forced-choice, 9-category normal distribution. The assessor described the subject by placing descriptive cards in 1 of the categories, ranging from 1 (least descriptive) to 9 (most descriptive). The resiliency scale was indexed by 11 items suggested by Eisenberg and colleagues (1997, 2003), for example, is resourceful in initiating activities, uses, and responds to reason. All items scored are listed in Supplemental Table S1. Scores are means of item totals with high scores indicative of more resiliency. Resiliency has been shown relatively stable over time (Hart et al., 1998), which was also true in our sample (3.0 to 17.9 years, $r=0.27, p<0.01$; Martel et al., 2009). We chose an early adolescence time point as predictor to outcome in early adulthood. To maximize variance, low and high resiliency groups were defined as lower and upper quartiles ( $n=17$ each).

Drinking and Drug Use Measures. The self-report Drinking and Drug History (DDHx, Zucker and Fitzgerald, 1994; Zucker et al., 1990) was completed by participants annually since age 11 . Data used were collected (mean $0.83 \pm 1.04$ years) from scan and reflect 
extent of drug involvement since age 11. Total drinking in past 6 months was calculated from DDHx counts of drinking days/ month multiplied by drinks usually consumed/drinking day. Alcohol problems (AP) were number of drinking problems (of possible 37 items) ever reported by the subject since age 11 . Number of illicit drugs ever used was quantified from a list of 18 drugs ever reported using over their lifetime. Cigarette smoking was determined from DDHx assessment or the more proximal prescan screening question, "Do you smoke?", and coded: 0 (nonsmoker, $n=23$ ) and 1 (smoker, $n=44)$. Substance use data were not normally distributed (Kolmogorov-Smirnov $[\mathrm{KS}]$ test, $p$-values $<0.032$ ) and were not normalized with standard transformations (square root, inverse; KS test, $p$-values $<0.035)$, and were therefore treated as a nonparametric variables. Age of onset was determined from the first annual DDHx on which the target reported first drink age and was normally distributed (KS test, $p=0.160)$.

Functional Magnetic Resonance Imaging (fMRI) Task. The nback task (Callicott et al., 1999) required subjects to continually update their mental set while responding to previously seen stimuli. Subjects viewed stimuli consisting of numbers (1 to 4) shown in random sequence displayed on a diamond-shaped box (see Fig. 1). On each trial, subjects press 1 of the 4 buttons to indicate the appropriate numeral. In the 0 -back condition, the correct response is the numeral currently displayed on the screen; for 2-back, the correct response is the numeral seen 2 screens back. The actual task included 5 conditions (0-, 1-, 2-, 3-back, and rest); each of 5 runs consisted of 30-second blocks of each load, pseudo-randomly ordered, with 15 stimuli per block. Total task time was approximately 15 minutes with all responses recorded.

MRI Data Acquisition. Whole-brain BOLD fMRI data were acquired on a 3.0 Tesla GE Signa system, Excite2 release (Milwaukee, WI), standard radio frequency coil. Functional imaging was performed using $\mathrm{T} 2 *$-weighted single-shot combined spiral in/out acquisition (Glover and Law, 2001): repetition time $=2,000 \mathrm{~ms}$, echo time $=30 \mathrm{~ms}$, flip angle $=90^{\circ}$, field-of-view $=0 \mathrm{~cm}, 64 \times 64$ matrix, slice thickness $=4 \mathrm{~mm}, 29$ slices. High-resolution anatomical T1 scans were acquired for spatial normalization. Motion was minimized with foam pads and emphasis on the importance of keeping still.

\section{Data Analysis}

Resiliency, Performance, and Drinking and Drug Use. Performance was measured by (i) response time (RT); and (ii) performance

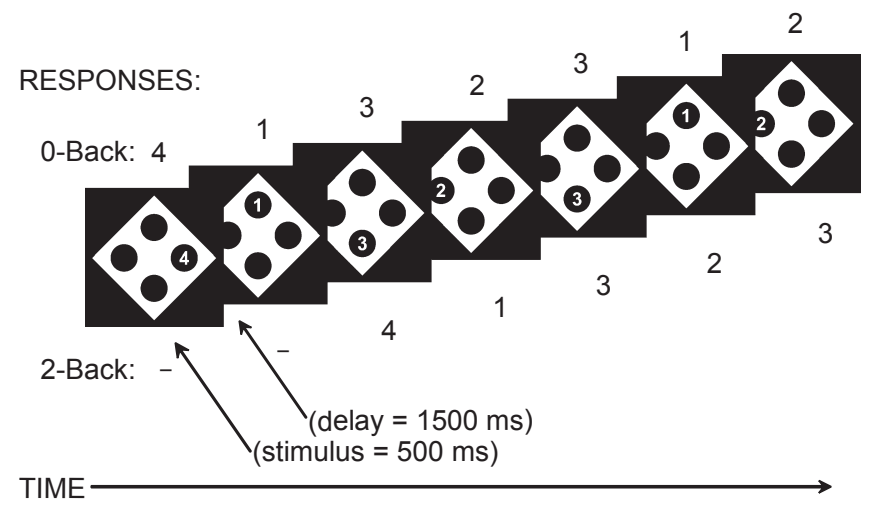

Fig. 1. Depiction of $n$-back working memory task showing correct responses for the 0-back and 2-back conditions. The 0-back response requires identifying the numeral currently presented while the 2-back response involves updating, temporarily maintaining, and storing information to recall numbers previously seen. decrement (PD) defined as the difference in correct response rates in 0-back and 2-back conditions (Jansma et al., 2000). The 2-back load was utilized as it maintained cognitive demand without exceeding capacity constraints (Callicott et al., 1999; Sweet et al., 2008), with satisfactory accuracy $(77.9 \pm 16.7 \%$ here $)$. RTs $<100 \mathrm{~ms}$ were considered anticipatory responding and removed from subsequent analyses. All performance measures were normally distributed (KS test, $p>0.07$ ) in SPSS version 17 (Chicago, IL).

Bivariate Pearson's or Spearman's rank correlations were used to test the associations between resiliency and performance and substance use measures. Significance (2-tailed) was established at $p<0.025$ accounting for multiple comparisons; RT and PD were highly correlated $(r=-0.332, p=0.008)$, as were all substance use/ vulnerability measures $(p>0.692, p<0.004)$. Independent sample $t$-tests were used to investigate differences in resiliency, performance, substance use, and vulnerability by gender, family history, and resiliency groups.

fMRI Data Preprocessing. Functional data were reconstructed using iterative image reconstruction (Fessler et al., 2005; Sutton et al., 2003) and motion-corrected using FSL 4.0 (Analysis Group, FMRIB, Oxford, UK). Runs exceeding 2-mm translation or $2^{\circ}$ rotation were excluded: 6 subjects had 1 run; 5 subjects had 2 runs removed. Number of subjects with excluded runs did not differ by resiliency or family history $(p>0.203)$, but trended by gender $\left(\chi^{2}=3.62, p=0.073\right)$. Age of onset and substance use did not differ between subjects with/without excluded runs $(p>0.234)$. Image processing was completed using statistical parametric mapping SPM2 (Wellcome Institute of Cognitive Neurology, Oxford, UK). Functional images were spatially normalized to standard stereotactic space as defined by the Montreal Neurological Institute (MNI). A 6-mm full-width-half-maximum Gaussian spatial smoothing kernel was applied.

Individual Task Statistical Maps and Group Correlation Analysis. A general linear model using SPM's canonical hemodynamic response function (HRF), modeled each condition (rest, 0-, 1-, 2-, and 3-back), and 6 motion regressors. Linear contrasts compared task load and 0-back. A second-level 1-sample $t$-test investigated task effect using 2-back versus 0-back contrasts. A second-level linear regression used individual resiliency scores as covariate and the same contrasts as dependent variable. To test our hypotheses, an a priori regions-of-interest (ROIs) mask (frontal-cingulate-parietalbasal ganglia; Bogacz et al., 2010; O'Reilly and Frank, 2006) was created using WFU Pickatlas (Maldjian et al., 2003). Regions of significant correlation within this mask were identified using a voxelwise threshold of $p<0.005$ uncorrected, combined with cluster size threshold of 61 contiguous voxels. This combined threshold provides protection against type I error (Forman et al., 1995) and was estimated with Monte Carlo simulation using AlphaSim (Douglas Ward, http://afni.nimh.nih.gov/pub/dist/doc/program_help/AlphaSim.html), giving an overall corrected threshold of $\bar{p}<0.05$. For identified clusters, activation data were extracted from individual contrast maps for correlation with behavioral measures.

Individual and Group Functional Connectivity Analysis. PPI determines regions whose time series of activation exhibit significant covariance with the seed region as a function of task manipulation, that is, 2-back versus 0-back. Regressing out the contribution of the seed region time series and the experimental context, the interaction is the contribution-dependent change in regional responses to the experimental factor (Friston et al., 1997), here working memory load. The clusters identified in the regression analysis (see Results), right pallidum, and STN, were used for PPI seed ROIs. For these ROIs, the time series data from the primary model were extracted for 5-mm-diameter spheres centered at [MNI coordinates: 20, -2, 6] for right pallidum and $[10,-14,-8]$ for STN. Anatomical 
validation of STN is based on work by Aron and Poldrack (2006). Each ROI time series was deconvolved with the canonical HRF to create neuronal time series (Gitelman et al., 2003). The PPI interaction term was the product of the neuronal time series and a contrast vector coding for main effect of task ( 1 for 2-back; -1 for 0 -back). This term was convolved with the HRF; PPI model regressors consisted of the interaction term, contrast vector and extracted time series plus motion regressors from the original design (Friston et al., 1997). Single-subject contrasts for the first regressor (interaction term) were calculated and used for second-level 2-sample $t$-tests evaluating low and high resiliency groups.

Significant group differences in functional coupling with seed ROIs, masked with the a priori mask described earlier, were determined using a voxelwise threshold of $p<0.005$, cluster threshold of 71 voxels, from an additional Monte Carlo estimation as previously described. For identified clusters, connectivity data were extracted from individual PPI maps for correlation with behavioral measures.

\section{RESULTS}

\section{Resiliency, Demographic, and Performance Data}

Table 1 presents demographic and working memory performance data for the entire group and the Low- and Highquartile resiliency groups separately. Mean resiliency score for the entire sample was $5.5 \pm 1.2$ (range, 3.1 to 7.2 ), in line with that of the entire MLS population: $5.8 \pm 0.8$ (range, 3.1 to 7.6), $n=496$. Performance and RTs were in agreement with previous work using the same $n$-back task (Jansma et al., 2000). No family history or gender effects were found for performance $(p>0.18)$. Resiliency did not differ by family history $(t=0.06, p=0.952)$, but women showed a trend for higher resiliency $(t=1.81, p=0.075)$; therefore, gender was added as a covariate in subsequent analyses.

Consistent with previous work from the entire MLS sample (Martel et al., 2007), Pearson's correlations showed positive correlation between resiliency and IQ $(r=0.39$, $p=0.001)$; IQ was added as a covariate in subsequent analyses. Resiliency had negative correlations with RT and PD (Table 2) maintaining significance when controlled for gender and IQ $(p<0.045)$.

\section{Resiliency, Vulnerability, and Substance Use Data}

There were no differences in AP, total drinking, illicit drugs used, or smoking by family history $(t<1.45$, $p \geq 0.151)$ or gender $(t<1.58, p>0.158)$. There was a trend for a difference in age of onset by family history $(\mathrm{FH}-/$ $\mathrm{FH}+: 15.6 \pm 2.2 / 14.3 \pm 2.7, p=0.056)$ but not gender $(\mathrm{M} / \mathrm{F}$ : $14.6 \pm 2.0 / 14.7 \pm 2.8, p=0.939)$. Resiliency negatively correlated with number of AP and number of illicit drugs used, was significantly lower in cigarette smokers, and showed a positive trend with age of onset (Table 2).

Table 1. Subject Characteristics

\begin{tabular}{|c|c|c|c|c|c|}
\hline & \multirow[b]{2}{*}{ Entire sample } & \multirow{2}{*}{$\begin{array}{c}\text { Low Resiliency } \\
\text { quartile }\end{array}$} & \multirow{2}{*}{$\begin{array}{l}\text { High Resiliency } \\
\text { quartile }\end{array}$} & \multicolumn{2}{|c|}{$\begin{array}{l}\text { Low/high group } \\
\text { differences }\end{array}$} \\
\hline & & & & $\chi^{2}$ or $t$ & $p$ \\
\hline$n$ & 67 & 17 & 17 & & \\
\hline Males/females & 43:24 & $10: 7$ & $5: 12$ & 2.98 & 0.084 \\
\hline Family history of alcoholism (Neg: Pos) ${ }^{a}$ & $20: 47$ & $6: 11$ & $7: 10$ & 0.13 & 0.724 \\
\hline Age (years) & $20.2(1.2)$ & $20.3(1.2)$ & $20.1(1.5)$ & 0.50 & 0.624 \\
\hline Wechsler intelligence scale IQ & $111(11)$ & $105(10)$ & $113(12)$ & 0.90 & 0.042 \\
\hline Resiliency (California Q-Sort) & $5.5(1.2)$ & $4.4(0.8)$ & $6.7(0.2)$ & -11.97 & 0.000 \\
\hline Alcohol abuse or dependence & 5 & 2 & 1 & 0.30 & 0.582 \\
\hline Marijuana abuse or dependence & 4 & 3 & 0 & 3.11 & 0.078 \\
\hline Other drug abuse or dependence & 2 & 2 & 0 & 2.00 & 0.157 \\
\hline Any substance use disorder $\mathrm{Dx}$ & 7 & 4 & 1 & 1.91 & 0.166 \\
\hline Conduct disorder Dx & 1 & 1 & 0 & 0.97 & 0.325 \\
\hline Attention deficit disorder Dx & 2 & 2 & 0 & 2.00 & 0.157 \\
\hline Any $D x^{C}$ & 7 & 4 & 1 & 1.91 & 0.166 \\
\hline Age of drinking onset (years) & $14.7(2.6)$ & $13.9(2.3)$ & $16.0(2.2)$ & 2.59 & 0.005 \\
\hline Number of alcohol problems & $5.2(5.6)$ & $6.9(5.8)$ & $2.8(5.2)$ & 2.17 & 0.038 \\
\hline Cigarette smoker (No:Yes) & $23: 44$ & $2: 15$ & $12: 5$ & 12.14 & 0.000 \\
\hline Illicit drugs used & $1.5(1.9)$ & $2.5(2.9)$ & $0.5(0.9)$ & 2.73 & 0.010 \\
\hline Total drinking past 6 months (drinks) & $29.9(41.5)$ & $32.5(33.5)$ & $20.4(39.7)$ & 1.91 & 0.065 \\
\hline \multicolumn{6}{|l|}{$n$-back working memory performance } \\
\hline 0-back & $601(114)$ & $688(121)$ & $515(49)$ & 5.41 & 0.000 \\
\hline 2-back & $290(104)$ & 349 (156) & $241(62)$ & 2.62 & 0.014 \\
\hline \multicolumn{6}{|l|}{ Correct response rate (\%) } \\
\hline 0-back & $86(7)$ & $88(5)$ & $85(8)$ & 1.57 & 0.127 \\
\hline 2-back & $78(15)$ & $74(18)$ & $82(17)$ & -1.26 & 0.216 \\
\hline \multicolumn{6}{|l|}{ Performance decrement (\%) } \\
\hline 0-back to 2-back & $8(17)$ & $15(19)$ & $3(19)$ & -1.68 & 0.103 \\
\hline
\end{tabular}

Neg, negative; Pos, positive; Dx, diagnosis; numbers displayed as: mean (standard deviation).

Bold text indicate significant differences between groups.

aFamily history positive: At least one parent with an alcohol use disorder based on DSM-IV criteria over the course of the youth's life.

bIncludes alcohol, marijuana, and/or other drug abuse or dependence.

'Includes conduct disorder, attention deficit disorder, and/or any substance use disorder. 
Table 2. Statistics for Relationships Between Resiliency with Working Memory Performance, Age of Onset, and Drinking and Drug Use for Entire Sample $(n=67)$

\begin{tabular}{lcc}
\hline & \multicolumn{2}{c}{ Correlations } \\
\cline { 2 - 3 } & $t$ or $\rho$ & $p$ \\
\hline Response time, 0-back & -0.504 & $<0.001^{\mathrm{a}}$ \\
Response time, 2-back & -0.371 & $0.003^{\mathrm{a}}$ \\
Performance decrement (0-back to 2-back) & -0.335 & $0.007^{\mathrm{a}}$ \\
Age of drinking onset & 0.216 & 0.08 \\
Number of alcohol problems & -0.292 & $0.017^{\mathrm{a}}$ \\
Illicit drugs used & -0.336 & $0.005^{\mathrm{a}}$ \\
Total drinking past 6 months & -0.199 & 0.11 \\
\cline { 2 - 3 } & Independent sample \\
& & test \\
\hline
\end{tabular}

a Survives correction for multiple comparisons.

Low and High resiliency groups did not differ by gender or family history, but did differ in reaction times and all substance use measures except total drinking in the past 6 months.

\section{Neuroimaging Results}

Effect of Task in 2-Back Working Memory. Second-level analysis for the entire sample $(n=67)$ revealed working memory task activation occurred in right prefrontal and anterior cingulate cortices, inferior parietal lobe, and left inferior frontal gyrus similar to previous studies (Braver et al., 1997; Callicott et al., 1999; Jansma et al., 2000; Owen et al., 2005). Task-related reductions in activation were found in posterior cingulate cortex, medial frontal regions, and bilateral pre-/postcentral gyri similar to previous work (Hampson et al., 2006). See Fig. 2 for 2-back versus 0-back contrast mappings and Table S2.

Correlation of Resiliency with 2-Back Task-Related Regions. Resiliency correlated with reduced activation in right pallidum and STN (see Table 3). At a more lenient threshold, $p<0.005$ uncorrected, voxel extent 50 , this effect also held in the left STN and pallidum. Figure 3 shows STN and pallidum ROIs and extracted data plotted against resiliency.

Post hoc analysis of extracted ROI data was conducted excluding subjects with any diagnosis of substance use disorder, conduct disorder, or ADHD $(n=7: 2 \mathrm{FH}-/ 5 \mathrm{FH}+$, resulting in $n=60$ ). Resiliency remained significantly correlated with both regions at $p<0.005$, confirming that the effects of externalizing disorders were not driving these correlations. Additional post hoc regression of resiliency with STN and pallidum activation maintained significance controlling for IQ $(p<0.001)$ and gender $(p<0.028)$.

\section{Relationship Between Activation Data and Behavioral} Measures. Right STN activation showed a positive trend with 2-back PD $(r=0.22, p=0.089)$ and no correlations with RT. No correlations were found between substance use, AP, age of onset, and activation across the entire sample $(p>0.68)$ or within gender, family history, or resiliency groups $(p>0.14)$.

PPI Analysis of Functional Connectivity with Right Pallidum. The test comparing Low and High resiliency quartiles revealed no clusters having connectivity differences meeting significance criteria.

PPI Analysis of Functional Connectivity with Right $S T N$. The Low and High resiliency contrasts revealed the Low group had stronger connectivity between right STN and a cluster in right median cingulate (Brodmann Area [BA] 23), an area with reduced activation during 2-back demand, see Table 3. Post hoc regression maintained significance when controlling for IQ and gender $(F=19.03$, $p<0.001)$. At a more lenient threshold, $p<0.005$ uncorrected, voxel extent 25 , a cluster in left median cingulate was identified, see Fig. 4. The High and Low contrasts had no clusters meeting significance criteria.

Relationship Between Connectivity Data and Behavioral Measures. For the entire sample, right STN-right median cingulate connectivity correlated with 0 -back RT $(r=0.30$, $p=0.016$ ), but with no other performance measures

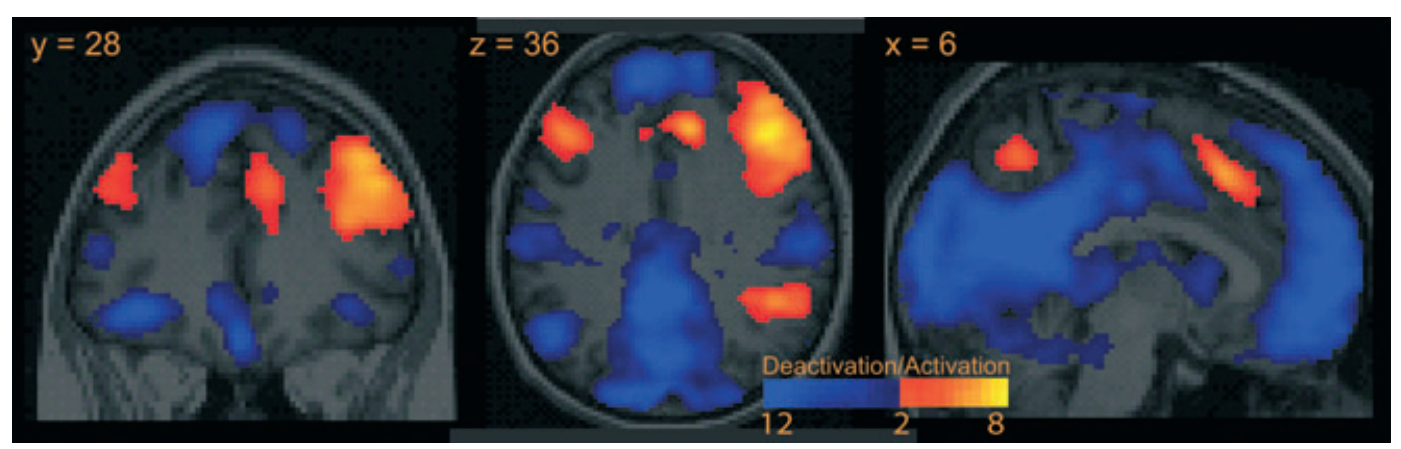

Fig. 2. Group whole-brain contrast maps for 2-back versus 0-back contrast for working memory task, displayed at a threshold of $p<0.05$ false discovery rate corrected and minimum cluster size of 10 , coordinates in Montreal Neurological Institute space. Orange region represents regions more activated during 2-back working memory relative to the 0 -back task while blue regions reflect the opposite relationship. 
Table 3. Brain Regions Identified in Whole Brain Analyses During 2-Back Versus 0-Back Working Memory Task

\begin{tabular}{|c|c|c|c|c|}
\hline & $\begin{array}{c}\text { MNI space } \\
\quad x, y, z\end{array}$ & Cluster extent & $\begin{array}{c}\text { Peak } \\
t\end{array}$ & Voxel level $p$ (uncorrected) \\
\hline \multicolumn{5}{|l|}{$\begin{array}{l}\text { Correlation with resiliency } \\
\text { for entire sample }(n=67)^{\mathrm{a}} \\
\text { Negative correlations }\end{array}$} \\
\hline R Pallidum & $20,-2,6$ & 247 & 4.1 & $<0.001$ \\
\hline R STN & $10,-14,-8$ & 77 & 3.7 & $<0.001$ \\
\hline \multirow{2}{*}{\multicolumn{5}{|c|}{ 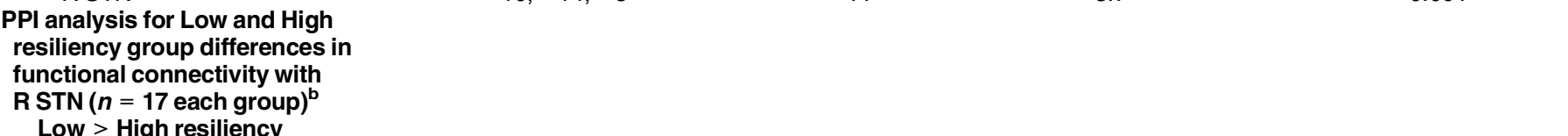 }} \\
\hline & & & & \\
\hline $\mathrm{R}$ median cingulate (BA 23) & $8,-24,34$ & 129 & 4.8 & $<0.001$ \\
\hline
\end{tabular}

MNI, Montreal Neurological Institute; R, right; STN, subthalamic nucleus; PPI, psychophysiological interaction; BA, Brodmann Area.

a Statistical threshold: corrected $p<0.05$, determined by dual threshold of voxel level $p<0.005$ uncorrected and cluster size $k>61$ contiguous voxels.

bStatistical threshold: corrected $p<0.05$, determined by dual threshold of voxel level $p<0.005$ uncorrected and cluster size $k>71$ contiguous voxels.

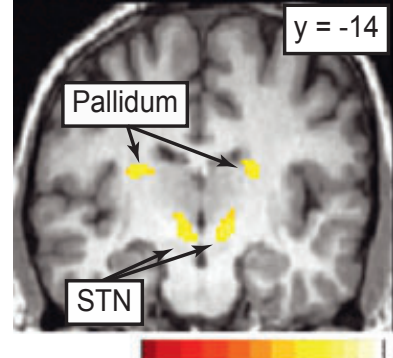

A t Value $0 \quad 1 \quad 2 \quad 3 \quad 4$
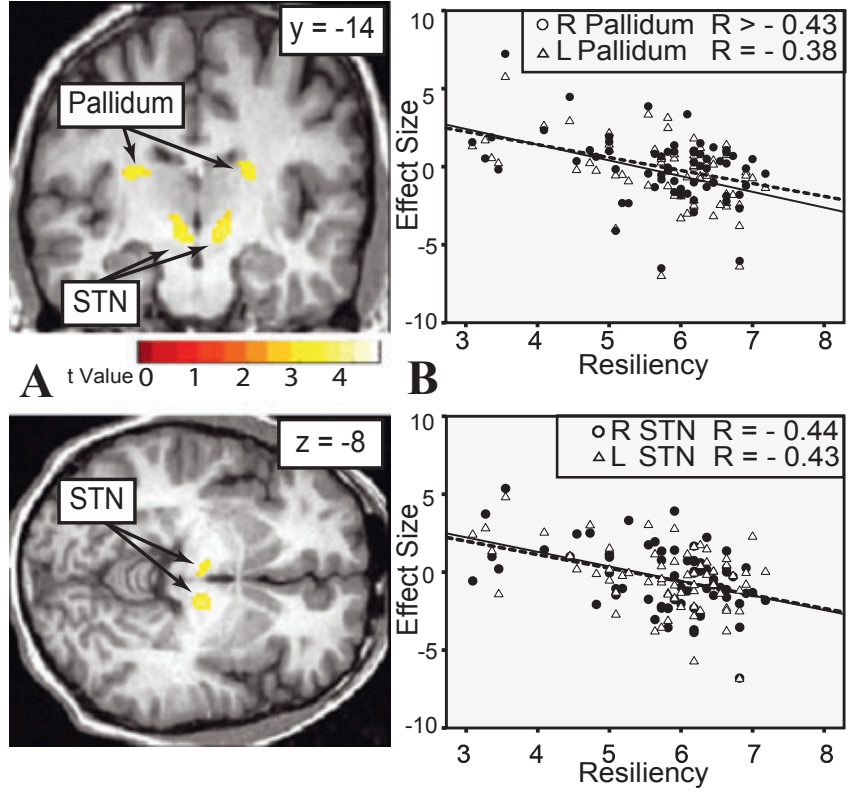

Fig. 3. (A) Subthalamic nucleus (STN) and pallidum regions of interest with negative correlation with resiliency measures from whole-brain group analysis displayed at a threshold of $p<0.005$ and minimum cluster size of 50, coordinates in Montreal Neurological Institute space. (B) Extracted bilateral pallidum and STN activity during 2-back versus 0-back condition of working memory plotted against individual resiliency measures for all subjects $(n=67)$.

$(p>0.169)$. There were no other correlations between connectivity and substance use or vulnerability measures $(p>0.077)$, across the entire sample or within family history/resiliency groups; therefore, these data do not support the hypothesized relationship between connectivity and substance use despite connectivity differences by resiliency group.

\section{DISCUSSION}

Resiliency has been defined as the ability to modulate impulses, affect expression, and behavior to adapt to environment context (Eisenberg et al., 2003) and identified as protective against behavioral and substance use problems
$\mathbf{A}$
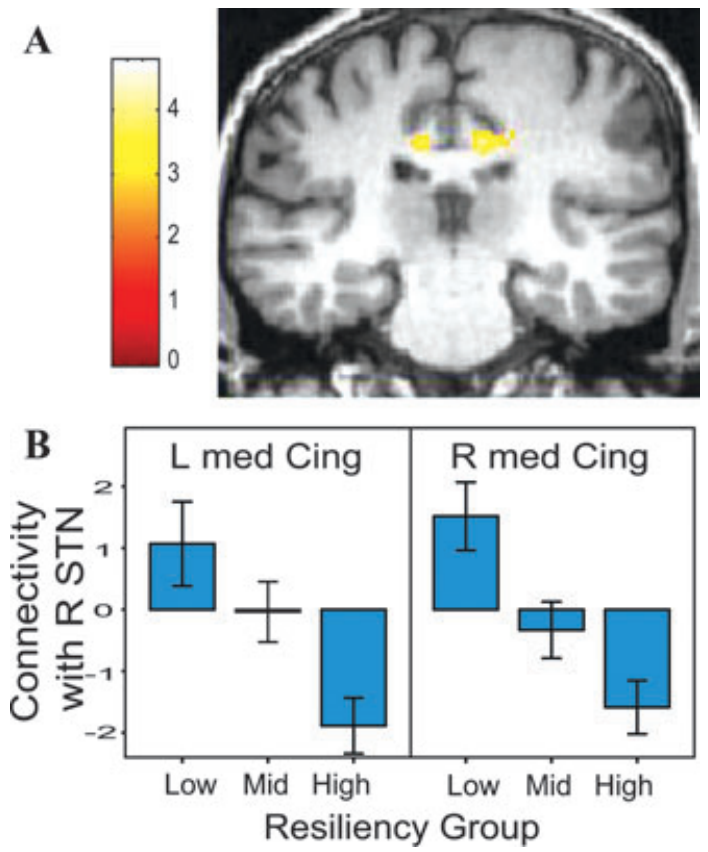

Fig. 4. (A) Bilateral median cingulate regions with different connectivity between Low and High resiliency groups ( $n=17$ each), displayed at a threshold of $p<0.005$, voxel extent $=25$, coordinates in Montreal Neurological Institute space. (B) Connectivity strength with right subthalamic nucleus (STN) for bilateral median cingulate regions of interest for Low $(n=17)$, Mid $(n=33)$, and High $(n=17)$ Resiliency Groups for 2-back versus 0-back working memory: Left cingulate region was identified at more lenient threshold as shown earlier. The Low resiliency quartile exhibited positive connectivity defined as stronger functional connectivity between regions for 2-back versus 0-back working memory, while the High resiliency had negative connectivity reflecting less functional connectivity between regions for 2-back versus 0-back task. Error bars: \pm 1 standard error.

(Block et al., 1988). Its neural basis has not been explored but may help identify developmental biomarkers of risk in psychiatric disorders. As earlier behavioral research linked resiliency in early childhood with later drinking and drunkenness onset in mid-adolescence, we anticipated a similar relationship in this study. It was present: resiliency in early adolescence was associated with a later onset of drinking, 
fewer AP, and less substance use in the transition years. These findings thus extend the continuity of this relationship from early childhood to early adulthood. Resiliency also correlated with faster reaction times and less decrement during increased cognitive demand, supporting a link between this trait and executive function. Therefore, resiliency in adolescence and drinking and drug use behaviors appear to be related; though, further study is needed to determine the direction of this association. Possibly, those who engage in early use of substances have cognitive changes that lead to altered working memory and reduced resiliency, a trait that is highly related to executive functioning. Alternatively, those who are most resilient when entering adolescence may resist the use of substances most efficiently.

The novel finding reported is a neural link shared between resiliency and working memory. Negative relationships were found between resiliency and activity in the interconnected basal ganglia structures, the STN and pallidum, during working memory. Likely because of their size and partial volume averaging with surrounding white matter, these nuclei were not detected in first-level task analyses, but were prominently localized in subsequent correlational analyses.

Investigation of task-related functional connectivity found Low and High resiliency groups differed in connectivity strength between the STN and median cingulate. The Low resiliency group had significantly more substance use, earlier onset of drinking, and more AP than the High group, as expected. However, these use and vulnerability measures were not related to connectivity; therefore, it is unclear whether this functional coupling represents a pathway linking resiliency, working memory, and substance use as predicted.

\section{Resiliency and Basal Ganglia During Working Memory}

Working memory is a limited capacity, constantly updated, system that temporarily maintains and stores information and interfaces thought processing, perception, and action (Baddeley, 2003) and suggested as the core cognitive element of higher-order regulation (Unsworth et al., 2009). The negative correlation between the regulatory trait resiliency and neural function of the STN and pallidum during working memory suggests an association with flexible adaptation of control during cognitive challenge. The STN, as a key basal ganglia structure, has reciprocal connections with the pallidum as part of the thalamocortical pathway and influences information processing within the basal ganglia and through projections to the frontal regions (Aron and Poldrack, 2006; Temel et al., 2005). The pallidum is considered the main output structure from the limbic system (Temel et al., 2005; Zhang et al., 2005).

Although the present study found only a trend for an association between STN activation and working memory, the findings are consistent with, and add to, an emerging literature. Experimental and clinical studies have highlighted interactions between higher-order cognitive processing and the STN. Animals with STN lesions show impaired working memory (El Massioui et al., 2007) and with disconnections between the STN and prefrontal cortex show reduced accuracy, increased perseveration, and slowed response (Chudasama et al., 2003). In patients with Parkinson's disease, deep brain stimulation of the STN has improved motor and some executive performance, including working memory, suggesting that STN stimulation was "releasing the brake" on frontal function (Jahanshahi et al., 2000, p. 1142) and supporting a role for the STN in higher-order cognitive regulation (Marceglia et al., 2011).

\section{STN and Substance Use}

The STN's influence may have relevance to substance use through regulation of behavior. Animals with STN lesions exhibit increased impulsive action, decreased impulsive choice (Uslaner and Robinson, 2006), and changes in motivation (Baunez et al., 2005; Winstanley et al., 2005). The lesion-induced changes increased motivation for natural (food) rewards and reduced motivation for drug (cocaine) rewards suggesting influence on incentive salience. Further, in "high-drinker" rats, STN lesions enhanced motivation for alcohol but further decreased it in "low-drinker" rats, suggesting a role involving motivation and individual preference (Lardeux and Baunez, 2007) with the authors proposing the STN as a target for treatment of addiction (Baunez et al., 2005). Again, patients with Parkinson's disease provide complementary information; STN stimulation, combined with reduction in dopaminergic treatment, has decreased pathological gambling (Ardouin et al., 2006; Bandini et al., 2007) and addiction (Witjas et al., 2005) in patients.

In this present study, there was no association found between STN or pallidum activation and levels of substance use as would be expected if resiliency were influencing these behaviors via this basal ganglia pathway. However, during this transition period into adulthood, drinking and drug use are at their highest (Johnston et al., 2004; Substance Abuse and Mental Health Services Administration, 2006), which may be overshadowing this relationship. Further studies are needed to determine who continues heightened use, who desists, the impact of liability over time, and whether the relationship between resiliency and basal ganglia activation may manifest as a protective factor.

\section{Connectivity of the STN During Working Memory}

Using PPI analysis, we found group differences in connectivity between the STN and median cingulate cortex, a default network region (Fransson and Marrelec, 2008), when contrasting a low-level (0-back) and a cognitively demanding (2-back) task. In the High resiliency group, these regions showed greater coupling in 0-back than in 2-back condition, whereas the Low resiliency group showed the opposite pattern. A recent PET study showed that stimulation of the STN decreased metabolism in a large region of the cingulate gyrus, centered in BA 24 and encompassing the median 
cingulate region identified in the present study, substantiating a link between these regions (Le Jeune et al., 2010). Anatomically, in nonhuman primates, the cingulate regions of BA 23 (controlling movement execution) and BA 24 (controlling higher cognitive aspects of movement) both send projections to the STN providing integrated motor information to the basal ganglia (Takada et al., 2001). Consistent with this, we found that connectivity between the STN and median cingulate was related to increased processing speed during the low demand 0-back condition. As an influence on interregional communication efficiency, this connectivity may represent a pathway linking resiliency and flexible implementation.

\section{Limitations}

Some limitations to this study should be noted. First, PPI does not yield information regarding causal relationships. The coupling between the STN and median cingulate infers interregional correlations, but does not identify direction or even whether other, unmeasured regions are driving activation at both loci. Additionally, resiliency could be argued to influence motivation, instead of, or in addition to, working memory. However, previous work by our group found consistent relationships between resiliency and other measures of executive functioning including response inhibition, interference control, and planning (Martel et al., 2007), supporting a relationship with performance. In addition, we did not find differences in current levels of substance use based on family history. Some studies have found increased drinking during young adulthood in $\mathrm{FH}+$ subjects (Harford et al., 1992; LaBrie et al., 2010) while others have not (Engs, 1990; Schuckit and Sweeney, 1987). As density of family history has been shown to moderate alcohol outcomes (Conway et al., 2003), the definition of liability one uses may impact findings. Familial risk is defined in this study as at least 1 parent with alcohol abuse or dependence, in contrast to other definitions (e.g., any biological relative with a "significant" drinking problem; LaBrie et al., 2010) or graduated scales (i.e., Engs, 1990; Harford et al., 1992; Schuckit and Sweeney, 1987). Importantly, another longitudinal study, which used FH criteria similar to this study, found that despite the absences of a family history effect on drinking at baseline (mean, 18.5 years), $\mathrm{FH}+$ subjects were less likely to transition out of heavy drinking (Jackson et al., 2001). We expect that continued longitudinal examination of outcomes, which is under way in this sample, will reveal the family history, as well as the resiliency, groups diverging as they exit the current high-usage period. We did find a trend for earlier age of onset of drinking in the $\mathrm{FH}+$ sample, suggesting that they are indeed at heightened liability for poor outcome.

\section{CONCLUSION}

Alcohol and drug use are outcomes of decisions supported by both cognitive and behavioral functions; the young adults in our study with early high resiliency were less likely to smoke, had tried fewer illicit drugs, and had fewer AP than their less resilient counterparts independent of familial liability. The STN may represent a neural link between individual resiliency and cognitive processing, potentially influencing substance abuse risk. Our PPI analysis linking resiliency with connectivity strength between the STN and cingulate regions potentially represents efficiency of communication between salience assigned by limbic regions and flexible adaptation facilitated by cognitive neural circuits. The extensive developmental time span of the resiliency/substance involvement relationship suggests that neural connections may be present considerably earlier than observed here. Other studies will need to examine this possibility.

\section{ACKNOWLEDGMENTS}

This work was supported by NIH grants T32 AA07477 to RAZ, K01 DA020088 to MMH, R01 AA12217 and R37 AA07065 to RAZ, and the Phil F. Jenkins Foundation award to J-KZ.

\section{DISCLOSURES}

The authors declare that, except for income received from our primary employer, no financial support or compensation has been received from any individual or corporate entity over the past 3 years for research or professional service, and there are no personal financial holdings that could be perceived as constituting a potential conflict of interest, with the exceptions below: Dr. Zubieta, Consultant, Eli Lilly Co, Merck, Johnson \& Johnson.

\section{REFERENCES}

Ardouin C, Voon V, Worbe Y, Abouazar N, Czernecki V, Hosseini H, Pelissolo A, Moro E, Lhommée E, Lang AE, Agid Y, Benabid A-L, Pollak P, Mallet L, Krack P (2006) Pathological gambling in Parkinson's disease improves on chronic subthalamic nucleus stimulation. Mov Disord 21:1941-1946.

Aron AR, Poldrack RA (2006) Cortical and subcortical contributions to stop signal response inhibition: role of the subthalamic nucleus. J Neurosci 26:2424-2433.

Baddeley A (2003) Working memory: looking back and looking forward. Nat Rev Neurosci 4:829-839.

Ballanger B, Eimeren Tv, Moro E, Lozano AM, Hamani C, Boulinguez P, Pellecchia G, Houle S, Poon YY, Lang AE, Strafella AP (2009) Stimulation of the subthalamic nucleus and impulsivity: release your horses. Ann Neurol 66:817-824.

Bandini F, Primavera A, Pizzorno M, Cocito L (2007) Using STN DBS and medication reduction as a strategy to treat pathological gambling in Parkinson's disease. Parkinsonism Relat Disord 13:369-371.

Barkley RA (1997) Behavioral inhibition, sustained attention, and executive functions: constructing a unifying theory of ADHD. Psychol Bull 121: 65-94.

Baunez C, Dias C, Cador M, Amalric M (2005) The subthalamic nucleus exerts opposite control on cocaine and 'natural' rewards. Nat Neurosci 8:484-489.

Block J, Block J (1980) The California Q-set: orientation and introduction. Series The California Q-set: Orientation and Introduction. University of California, Berkeley. 
Block J, Block JH, Keyes S (1988) Longitudinally foretelling drug usage in adolescence: early childhood personality and environmental precursors. Child Dev 59:336-355.

Bogacz R, Wagenmakers E-J, Forstmann BU, Nieuwenhuis S (2010) The neural basis of the speed-accuracy tradeoff. Trends Neurosci 33:10-16.

Bonomo YA, Bowes G, Coffey C, Carlin JB, Patton GC (2004) Teenage drinking and the onset of alcohol dependence: a cohort study over seven years. Addiction 99:1520-1528.

Botvinick MM, Braver TS, Barch DM, Carter CS, Cohen JD (2001) Conflict monitoring and cognitive control. Psychol Rev 108:624-652.

Braver TS, Cohen JD, Nystrom LE, Jonides J, Smith EE, Noll DC (1997) A parametric study of prefrontal cortex involvement in human working memory. Neuroimage 5:49-62.

Bush G, Whalen PJ, Rosen BR, Jenike MA, McInerney SC, Rauch SL (1998) The counting stroop: an interference task specialized for functional neuroimaging-validation study with functional MRI. Hum Brain Mapp 6:270-282.

Callicott JH, Mattay VS, Bertolino A, Finn K, Coppola R, Frank JA, Goldberg TE, Weinberger DR (1999) Physiological characteristics of capacity constraints in working memory as revealed by functional MRI. Cereb Cortex 9:20-26.

Caspi A, Block J, Block JH, Klopp B, Lynam D, Moffitt TE, StouthamerLoeber M (1992) A "common-language" version of the California Child Q-Set for personality assessment. Psychol Assess 4:512-523.

Chang C, Crottaz-Herbette S, Menon V (2007) Temporal dynamics of basal ganglia response and connectivity during verbal working memory. Neuroimage 34:1253-1269.

Chudasama Y, Baunez C, Robbins TW (2003) Functional disconnection of the medial prefrontal cortex and subthalamic nucleus in attentional performance: evidence for corticosubthalamic interaction. J Neurosci 23:5477-5485.

Conway KP, Swendsen JD, Merikangas KR (2003) Alcohol expectancies, alcohol consumption, and problem drinking: the moderating role of family history. Addict Behav 28:823-836.

Corral M, Holguin S, Cadaveira F (1999) Neuropsychological characteristics in children of alcoholics: familial density. J Stud Alcohol Drugs 60: 509-513.

Dick DM, Aliev F, Viken R, Kaprio J, Rose RJ (2011) Rutgers alcohol problem index scores at age 18 predict alcohol dependence diagnoses 7 years later. Alcohol Clin Exp Res 35:1011-1014.

Eisenberg N, Guthrie IK, Fabes RA, Reiser M, Murphy BC, Holgren R, Maszk P, Losoya S (1997) The relations of regulation and emotionality to resiliency and competent social functioning in elementary school children. Child Dev 68:295-311.

Eisenberg N, Guthrie IK, Fabes RA, Shepard S, Losoya S, Murphy B, Jones S, Poulin R, Reiser M (2000) Prediction of elementary school children's externalizing problem behaviors from attentional and behavioral regulation and negative emotionality. Child Dev 71:1367-1382.

Eisenberg N, Morris AS (2002) Children's emotion-related regulation. Adv Child Dev Behav 30:189-229.

Eisenberg N, Valient C, Fabes RA, Smith CL, Reiser M, Shepard SA, Losoya SH, Guthrie IK, Murphy BC, Cumberland AJ (2003) The relations of effortful control and ego control to children's resiliency and social functioning. Dev Psychol 39:761-776.

El Massioui N, Chéruel F, Faure A, Conde F (2007) Learning and memory dissociation in rats with lesions to the subthalamic nucleus or to the dorsal striatum. Neuroscience 147:906-918.

Engs RC (1990) Family background of alcohol abuse and its relationship to alcohol consumption among college students: an unexpected finding. J Stud Alcohol 51:542-547.

Fessler J, Lee S, Olafsson V, Shi H, Noll D (2005) Toeplitz-based iterative image reconstruction for MRI with correction for magnetic field inhomogeneity. IEEE Trans Signal Process 53:3393-3402.

Finn PR, Justus A, Mazas C, Steinmetz JE (1999) Working memory, executive processes and the effects of alcohol on Go/No-Go learning: testing a model of behavioral regulation and impulsivity. Psychopharmacology 146:465-472.
Forman SD, Cohen JD, Fitzgerald M, Eddy WF, Mintun MA, Noll DC (1995) Improved assessment of significant activation in functional magnetic resonance imaging (fMRI): use of a cluster-size threshold. Magn Reson Med 33:636-647.

Forstmann BU, Anwander A, Schäfer A, Neumann J, Brown S, Wagenmakers E-J, Bogacz R, Turner R (2010) Cortico-striatal connections predict control over speed and accuracy in perceptual decision making. Proc Natl Acad Sci USA 107:15916-15920.

Frank MJ (2006) Hold your horses: a dynamic computational role for the subthalamic nucleus in decision making. Neural Netw 19:1120-1136.

Frank MJ, Scheres A, Sherman SJ (2007) Understanding decision-making deficits in neurological conditions: insights from models of natural action selection. Philos Trans R Soc Lond B Biol Sci 362:1641-1654.

Fransson P, Marrelec G (2008) The precuneus/posterior cingulate cortex plays a pivotal role in the default mode network: evidence from a partial correlation network analysis. Neuroimage 42:1178-1184.

Friston KJ, Buechel C, Fink GR, Morris J, Rolls E, Dolan RJ (1997) Psychophysiological and modulatory interactions in neuroimaging. Neuroimage 6:218-229.

Gitelman DR, Penny WD, Ashburner J, Friston KJ (2003) Modeling regional and psychophysiologic interactions in fMRI: the importance of hemodynamic deconvolution. Neuroimage 19:200-207.

Glover GH, Law CS (2001) Spiral-in/out BOLD fMRI for increased SNR and reduced susceptibility artifacts. Magn Reson Med 46:515-522.

Grant BF, Dawson DA (1997) Age at onset of alcohol use and its association with DSM-IV alcohol abuse and dependence: results from the national longitudinal alcohol epidemiologic survey. J Subst Abuse 9:103-110

Greicius MD, Menon V (2004) Default-mode activity during a passive sensory task: uncoupled from deactivation but impacting activation. J Cogn Neurosci 16:1484-1492.

Hampson M, Driesen NR, Skudlarski P, Gore JC, Constable RT (2006) Brain connectivity related to working memory performance. J Neurosci 26:13338-13343.

Harford TC, Parker DA, Grant BF (1992) Family history, alcohol use and dependence symptoms among young adults in the United States. Alcohol Clin Exp Res 16:1042-1046.

Hart D, Keller M, Edelstein W, Hofmann V (1998) Childhood personality influences on social-cognitive development: a longitudinal study. J Pers Soc Psychol 74:1278-1289.

Hingson RW, Heeren T, Winter MR (2006) Age at drinking onset and alcohol dependence: age at onset, duration, and severity. Arch Pediatr Adolesc Med 160:739-746.

Jackson KM, Sher KJ, Gotham HJ, Wood PK (2001) Transitioning into and out of large-effect drinking in young adulthood. J Abnorm Psychol 110:378-391.

Jahanshahi M, Ardouin CMA, Brown RG, Rothwell JC, Obeso J, Albanese A, Rodriguez-Oroz MC, Moro E, Benabid AL, Pollak P, LimousinDowsey P (2000) The impact of deep brain stimulation on executive function in Parkinson's disease. Brain 123:1142-1154.

Jansma JM, Ramsey NF, Coppola R, Kahn RS (2000) Specific versus nonspecific brain activity in a parametric N-back task. Neuroimage 12 688-697.

Johnston L, O'Malley P, Bachman J, Schulenberg JE (2004) Monitoring the Future national survey results on drug use, 1975-2003. Volume I: Secondary school students, in Series Monitoring the Future National Survey Results on Drug Use, 1975-2003. National Institute on Drug Abuse, Bethesda, MD.

Krueger RF (1999) Personality traits in late adolescence predict mental disorders in early adulthood: a prospective-epidemiological study. J Pers 67:39-65.

LaBrie JW, Migliuri S, Kenney SR, Lac A (2010) Family history of alcohol abuse associated with problematic drinking among college students. Addict Behav 35:721-725.

Lardeux S, Baunez C (2007) Alcohol preference influences the subthalamic nucleus control on motivation for alcohol in rats. Neuropsychopharmacology 33:634-642. 
Le Jeune F, Péron J, Grandjean D, Drapier S, Haegelen C, Garin E, Millet B, Vérin M (2010) Subthalamic nucleus stimulation affects limbic and associative circuits: a PET study. Eur J Nucl Med Mol Imaging 37:1512-1520.

Maldjian JA, Laurienti PJ, Kraft RA, Burdette JH (2003) An automated method for neuroanatomic and cytoarchitectonic atlas-based interrogation of fMRI data sets. Neuroimage 19:1233-1239.

Marceglia S, Fumagalli M, Priori A (2011) What neurophysiological recordings tell us about cognitive and behavioral functions of the human subthalamic nucleus. Expert Rev Neurother 11:139-149.

Martel MM, Nigg JT, Wong MM, Fitzgerald HE, Jester JM, Puttler LI, Glass JM, Adams KM, Zucker RA (2007) Childhood and adolescent resiliency, regulation, and executive functioning in relation to adolescent problems and competence in a high-risk sample. Dev Psychopathol 19: 541-563.

Martel MM, Pierce L, Nigg JT, Jester JM, Adams K, Puttler LI, Buu A, Fitzgerald H, Zucker RA (2009) Temperament pathways to childhood disruptive behavior and adolescent substance abuse: testing a cascade model. J Abnorm Child Psychol 37:363-373.

National Institute on Alcohol Abuse and Alcoholism (2000) Alcohol involvement over the life course, in NIAAA, Tenth Special Report to the U.S. Congress on Alcohol and Health: Highlights from current research, NIAAA, Tenth Special Report to the U.S. Congress on Alcohol and Health: Highlights from current research, pp 28-53, U.S. Department of Health and Human Services, Bethesda, MD.

Nigg JT (2000) On inhibition/disinhibition in developmental psychopathology: views from cognitive and personality psychology and a working inhibition taxonomy. Psychol Bull 126:220-246.

O'Reilly RC, Frank MJ (2006) Making working memory work: a computational model of learning in the prefrontal cortex and basal ganglia. Neural Comput 18:283-328.

Owen AM, McMillan KM, Laird AR, Bullmore E (2005) N-back working memory paradigm: a meta-analysis of normative functional neuroimaging studies. Hum Brain Mapp 25:46-59.

Ozkaragoz T, Satz P, Noble EP (1997) Neuropsychological functioning in sons of active alcoholic, recovering alcoholic, and social drinking fathers. Alcohol 14:31-37.

Pennington BF, Ozonoff S (1996) Executive functions and developmental psychopathology. J Child Psychol Psychiatry 37:51-87.

Raichle ME, MacLeod AM, Snyder AZ, Powers WJ, Gusnard DA, Shulman GL (2001) A default mode of brain function. Proc Natl Acad Sci USA 98:676-682.

Rothbart MK, Ahadi SA, Evans DE (2000) Temperament and personality: origins and outcomes. J Pers Soc Psychol 78:122-135.

Schuckit MA, Sweeney S (1987) Substance use and mental health problems among sons of alcoholics and controls. J Stud Alcohol 48:528-534.

Shedler J, Block J (1990) Adolescent drug use and psychological health: a longitudinal inquiry. Am Psychol 45:612-630.

Smith EE, Jonides J (1997) Working memory: a view from neuroimaging. Cogn Psychol 33:5-42.

Spadoni AD, Norman AL, Schweinsburg AD, Tapert SF (2008) Effects of family history of alcohol use disorders on spatial working memory BOLD response in adolescents. Alcohol Clin Exp Res 32:1135-1145.

Substance Abuse and Mental Health Services Administration (2006) Results From the 2005 National Survey on Drug Use and Health: National Findings. NSDUH Series H-30, DHHS Pub. No. SMA 06-4194, in Series Results From the 2005 National Survey on Drug Use and Health: National Findings. NSDUH Series H-30, DHHS Pub. No. SMA 06-4194, SAMHSA, Office of Applied Studies, Rockville, MD.

Sutton BP, Noll DC, Fessler JA (2003) Fast, iterative image reconstruction for MRI in the presence of field inhomogeneities. IEEE Trans Med Imaging 22:178-188.

Sweet LH, Paskavitz JF, Haley AP, Gunstad JJ, Mulligan RC, Nyalakanti PK, Cohen RA (2008) Imaging phonological similarity effects on verbal working memory. Neuropsychologia 46:1114-1123.

Takada M, Tokuno H, Hamada I, Inase M, Ito Y, Imanishi M, Hasegawa N, Akazawa T, Hatanaka N, Nambu A (2001) Organization of inputs from cingulate motor areas to basal ganglia in macaque monkey. Eur $\mathbf{J}$ Neurosci 14:1633-1650.

Temel Y, Blokland A, Steinbusch HWM, Visser-Vandewalle V (2005) The functional role of the subthalamic nucleus in cognitive and limbic circuits. Prog Neurobiol 76:393-413.

Unsworth N, Redick TS, Heitz RP, Broadway JM, Engle RW (2009) Complex working memory span tasks and higher-order cognition: a latent-variable analysis of the relationship between processing and storage. Memory 17:635-654.

Uslaner JM, Robinson TE (2006) Subthalamic nucleus lesions increase impulsive action and decrease impulsive choice - mediation by enhanced incentive motivation? Eur J Neurosci 24:2345-2354.

Viner RM, Taylor B (2007) Adult outcomes of binge drinking in adolescence: findings from a UK national birth cohort. J Epidemiol Community Health 61:902-907.

Winstanley CA, Baunez C, Theobald DE, Robbins TW (2005) Lesions to the subthalamic nucleus decrease impulsive choice but impair autoshaping in rats: the importance of the basal ganglia in Pavlovian conditioning and impulse control. Eur J Neurosci 21:3107-3116.

Witjas T, Baunez C, Henry JM, Delfini M, Regis J, Cherif AA, Peragut JC, Azulay JP (2005) Addiction in Parkinson's disease: impact of subthalamic nucleus deep brain stimulation. Mov Disord 20:1052-1055.

Wong MM, Nigg JT, Zucker RA, Puttler LI, Fitzgerald HE, Jester JM, Glass JM, Adams K (2006) Behavioral control and resiliency in the onset of alcohol and illicit drug use: a prospective study from preschool to adolescence. Child Dev 77:1016-1033.

Yeung N, Botvinick MM, Cohen JD (2004) The neural basis of error detection: conflict monitoring and the error-related negativity. Psychol Rev 111:931-959.

Zhang Y, Bailey KR, Toupin MM, Mair RG (2005) Involvement of ventral pallidum in prefrontal cortex-dependent aspects of spatial working memory. Behav Neurosci 119:399-409.

Zucker R, Fitzgerald H, Noll R (1990) Drinking and Drug History (Revised edition, Version 4), University of Michigan Department of Psychiatry, Addiction Research Center, Ann Arbor.

Zucker RA, Ellis DA, Fitzgerald HE, Bingham CR, Sanford K (1996) Other evidence for at least two alcoholisms II: life course variation in antisociality and heterogeneity of alcoholic outcome. Dev Psychopathol 8:831-848.

Zucker RA, Fitzgerald HE (1994) Drinking and Drug History Form for Children. University of Michigan Department of Psychiatry, Addiction Research Center, Ann Arbor.

Zucker RA, Fitzgerald HE, Refior SK, Puttler LI, Pallas DM, Ellis DA (2000) The clinical and social ecology of childhood for children of alcoholics: Description of a study and implications for a differentiated social policy, in Children of addiction: Research, Health and Policy Issues. (Fitzgerald HE, Lester BM, Zuckerman BS eds), pp 109-141. Routledge Falmer, New York.

\section{SUPPORTING INFORMATION}

Additional Supporting Information may be found in the online version of this article:

Table S1. California Child Q-Sort Resiliency Scale Items

Table S2. Brain Region Significance for 2-Back versus 0-Back Working Memory Group Level Contrast

Please note: Wiley-Blackwell is not responsible for the content or functionality of any Supporting Information supplied by the authors. Any queries (other than missing material) should be directed to the corresponding author for the article. 